\title{
Uma proposta metodológica para estimar o custo da poluição do ar nas análises de viabilidade de sistemas de transportes urbanos
}

\author{
Marcelo Camilli Landmann; Helena Ribeiro²; Csaba Deák ${ }^{3}$
}

\begin{abstract}
Resumo: O objetivo deste trabalho é apresentar um novo método para valoração monetária da poluição do ar para ser utilizado nas análises de viabilidade de projetos de transportes. Os métodos tradicionalmente utilizados, com base nos custos de saúde, envolvem várias etapas de cálculo, muita imprecisão, e são considerados muito complexos e onerosos. Além disso, os dados necessários nem sempre estão disponíveis nos países em desenvolvimento, o que tem levado a adaptações precárias dos resultados dos estudos feitos nos países desenvolvidos, com base na renda per capita, por exemplo, desconsiderando assim a dispersão dos poluentes e outras especificidades das regiões de estudo, como o grau de exposição e a pré-disposição da população local às doenças. O método proposto tem como base os custos do controle das emissões veiculares. Através de pesquisa de preços de catalisadores e dos custos de manutenção e fiscalização das emissões veiculares, e aplicando-se as equações de consumo de combustíveis em redes urbanas, chegouse a um modelo bastante simples e direto, que pode ser facilmente utilizado nos estudos de planejamento de transportes. Como dados de entrada são utilizados os valores de veículo*km, veículo*hora e velocidade média na rede, obtidos a partir de modelos de simulação de transportes. Finalmente, se assinala que o método proposto deriva de uma abordagem em que a conservação ambiental, mais do que mera questão de eficiência econômica, é uma condição necessária à própria reprodução da sociedade.
\end{abstract}

\begin{abstract}
The aim of this paper is to present a new method to estimate monetary values of air pollution, to be used in cost/benefit analysis of transport projects. The traditional damage-based methods are very complex, capital and data-intensive and present many uncertainties. Besides, data are not always available in developing countries to feed those damage-based methods, and technicians adapt the results estimated to USA and European countries just by applying a factor based in the differences of per capita revenue. But that is not realistic, because it does not consider the local issues like atmospheric dispersion, exposure and physical effects of air pollution on human health and materials. The proposed method is based on costs of vehicle emission control. By a simple formula based on fuel consumption and data from traffic models we can estimate the cost of air pollution through the market prices of catalytic conversers and the costs of maintenance and enforcement of vehicular emissions. Finally, it is pointed out that the new method arises from an approach where the environmental conservation, more than merely an economic efficiency issue, is a condition to society's reproduction.
\end{abstract}

\section{INTRODUÇÃO}

A poluição atmosférica é considerada um dos problemas ambientais mais graves nas grandes aglomerações urbanas. Ela é proveniente da emissão de centenas de gases tóxicos e materiais particulados emitidos a partir de fontes fixas e móveis, que em determinadas condições meteorológicas acumulam-se na baixa atmosfera, causando danos à saúde e degradação dos materiais. Os poluentes adentram no organismo humano através da respiração provocando desconforto, irritação das mucosas, alergias, doenças crônicas e até a morte. Eles também afetam os materiais, acelerando o desgaste dos fios das redes elétricas, dos metais em máquinas e equipamentos, e das pinturas e revestimentos das edificações.

O setor de transportes é apontado como um dos

\footnotetext{
${ }^{1}$ Marcelo Camilli Landmann, Programa de Ciência Ambiental da USP (e-mail: mlandmann@usp.br).

${ }^{2}$ Helena Ribeiro, Faculdade de Saúde Pública da USP (e-mail: lena@usp.br).

${ }^{3}$ Csaba Deák, Faculdade de Arquitetura e Urbanismo da USP (email: deak@usp.br).
}

Manuscrito recebido em 4/7/2007 e aprovado para publicação em 6/10/2007. Este artigo é parte de TRANSPORTES, volume $\mathrm{XV}$, número 1, junho de 2007. ISSN: 1415-7713. maiores causadores da poluição nas grandes metrópoles, principalmente dos países em desenvolvimento. No Brasil, durante as décadas de 1960 e 1970, a poluição do ar era majoritariamente proveniente das fontes industriais, porém este quadro mudou, e os transportes passaram a ser a principal fonte de emissão. Isto aconteceu porque houve uma acentuada redução das emissões industriais em meados da década de 1970, com a Lei 997 de maio de 1976, que forçou a implementação de políticas de controle até então inexistentes. (Ribeiro e Assunção, 2001). Por outro lado, as taxas de motorização e a população só fizeram aumentar. A redução das emissões veiculares começou somente na década de 1980, a partir da vigência do Proconve - Programa de Controle da Poluição do Ar Provocada por Veículos Automotores, com legislação federal iniciada pela resolução CONAMA $n^{\circ} 18$ de 6 de maio de 1986. O Proconve estabeleceu uma gradual redução nas emissões veiculares, e hoje um automóvel sai da fábrica dotado de equipamentos de controle que reduzem em até $94 \%$ os níveis de emissão em relação a um automóvel fabricado no Brasil no início do programa (Cetesb, 2006). Mudanças na composição dos combustíveis, e a adição de álcool à gasolina também influenciaram na redução nas emissões. Mesmo assim, 
os valores totais das emissões veiculares ainda são altos e os veículos (leves e pesados) são os responsáveis por $97 \%$ das emissões de monóxido de carbono (CO), 97\% dos hidrocarbonetos (HC), 97\% dos óxidos de nitrogênio $\left(\mathrm{NO}_{\mathrm{x}}\right), 40 \%$ de material particulado (MP) e 35\% de óxido de enxofre $\left(\mathrm{SO}_{\mathrm{x}}\right)$ na Região $\mathrm{Me}-$ tropolitana de São Paulo (Cetesb, 2006).

Apesar da poluição do ar causar inúmeros entraves ao desenvolvimento, não há uma metodologia claramente definida nem amplamente aceita para valorá-la. Os técnicos e as autoridades envolvidas com o tema quase sempre se deparam com dificuldades quando são solicitados a expressar monetariamente os custos dos danos ou os benefícios da redução das emissões nas análises de viabilidade econômico-financeira dos projetos. Com o aumento da preocupação global com as questões ambientais, e principalmente após a Declaração da Conferência das Nações Unidas sobre Meio Ambiente e Desenvolvimento em 1992, as análises dos benefícios ambientais assumiram maior importância, e atualmente, é recomendado pelos agentes de financiamento, como o Banco Mundial e o Banco Interamericano de Desenvolvimento, que os custos e benefícios ambientais apareçam nas contas das análises de viabilidade dos projetos e que sejam explicitamente valorados em termos monetários.

Entretanto, as metodologias para obtenção desses valores não são pré-determinadas pelos órgãos financiadores, ficando sua escolha como uma tarefa para os técnicos locais, que obviamente optam por aquela que se mostra mais adequada à sua disponibilidade de dados e recursos, desde que suficientemente consistentes e bem justificadas. Os indicadores mais utilizados para a avaliação dos benefícios ambientais dos projetos de transportes são, assim, as emissões veiculares e o ruído. Para a valoração monetária dos benefícios da redução das emissões veiculares existem algumas metodologias utilizadas internacionalmente, que têm como base os custos da poluição do ar na saúde e na degradação dos materiais. Os benefícios monetários da redução dos ruídos são de difícil mensuração, e muito pouco utilizados.

Nos estudos de viabilidade de projetos de transportes feitos no Brasil, pela ausência de estudos específicos para as condições brasileiras, são aplicados quase que diretamente os valores dos custos dos danos das emissões veiculares calculados para regiões urbanas dos EUA e Europa, com algumas adaptações. A metodologia que serve de referência para os projetos brasileiros é apresentada numa publicação bastante divulgada entre os profissionais de transportes, elaborada pela ANTP - Associação Nacional de Transporte Público, em conjunto com o IPEA - Instituto de Pesquisa Econômica Aplicada (1998). Na metodologia da ANTP, os valores calculados para os custos dos danos da poluição do ar nas cidades americanas, em US\$/kg de emissão de poluentes, aparecem convertidos em reais através de uma relação aproximada das rendas per capita brasileira e norte-americana. Estes valores foram utilizados nas análises de viabilidade dos principais projetos de transportes do país a partir da década de 1990, como a Linha 4 do Metrô de São Paulo, a linha Centro - Barra da Tijuca do Metrô do Rio de Janeiro, o Metrô de Fortaleza - METROFOR, entre outros. Os valores utilizados no cálculo dos benefícios da redução das emissões veiculares são: $\mathrm{R} \$$ 0,19/kg para o CO, R\$ 1,14/kg para o HC, R \$1,12/kg para o $\mathrm{NOx}$ e $\mathrm{R} \$$ 0,91 para o material particulado (ANTP, 1998).

No entanto, tal adaptação não é verossímil, pois não se trata simplesmente de fazer uma relação entre a renda per capita dos países. A metodologia clássica para estimar os valores monetários das reduções das emissões veiculares, normalmente apresentados em US $\$$ /kg de emissão ou em US\$/km, inclui procedimentos bastante complexos, e compreende várias etapas de cálculo envolvendo um grande número de variáveis, que nem sempre podem ser controladas. Além do inventário das emissões, também entram no processo de cálculo as condições geográficas e meteorológicas locais: ventos, temperatura, pressão, chuvas, insolação, relevo, rugosidade do terreno etc, usados para modelar a dispersão atmosférica, e a partir daí, estimar as concentrações finais de poluentes na atmosfera local e obter a relação com os danos causados pela poluição do ar em termos de doenças, mortes e prejuízos materiais. Em seguida, estes danos são monetizados. Nos estudos de projetos futuros, a etapa da dispersão da poluição do ar só pode ser feita através de modelos matemáticos, uma vez que se trata de projetos que ainda estão para serem implantados e, assim sendo, a redução ou o aumento das emissões não podem ser medidos diretamente nas estações de medição da qualidade do ar, mas obtidos pela simulação de cenários futuros. Valores monetários calculados para uma região não servem para outras regiões, pois a dispersão atmosférica é diferente em cada bacia, e é a dispersão que irá definir a concentração final dos gases e partículas poluentes na atmosfera. Ou seja, os danos em termos de perda de saúde e degradação de materiais acontecem quando são ultrapassados os limites das concentrações finais de poluentes na atmosfera, considerando a maior ou menor diluição dos poluentes emitidos pelas fontes.

Até o momento, ainda não existem no Brasil modelos de dispersão da poluição do ar devidamente calibrados para estimar as concentrações atuais e futuras de poluentes atmosféricos nas regiões de estudo. Algumas iniciativas estão acontecendo nas cidades de São Paulo (IAG / USP) e Rio de Janeiro (Renault / 
Petrobrás), mas ainda não há uma previsão para que os modelos se tornem operacionais. Isto porque a calibração dos modelos de dispersão envolve atividades que demandam tempo, recursos e profissionais especializados na obtenção e preparo dos dados, bem como na análise dos resultados. Também há uma grande carência de estudos sobre as metodologias para estimar custos ambientais direcionados para o setor de transportes, o que gera um certo distanciamento dos técnicos com essa questão e fragiliza o processo.

Neste sentido, o objetivo principal deste trabalho é trazer essa problemática à tona, e apresentar um novo método para valoração ambiental da poluição do ar proveniente dos transportes. O método apresentado tem como base os custos do controle das emissões veiculares, calculado através dos custos dos equipamentos mais os custos institucionais referentes aos gastos com implantação, manutenção e fiscalização de programas de controle das emissões.

Acreditamos que o método proposto, além de apresentar maior precisão e confiabilidade, poderá ser facilmente adotado nas análises de viabilidade de projetos de transportes, pois é um método simples e fácil de ser aplicado, uma vez que envolve variáveis diretamente mensuráveis e bastante familiares aos profissionais da área.

\section{VALORAÇÃO AMBIENTAL}

Segundo Ortiz (2003), as técnicas de valoração ambiental buscam medir as preferências das pessoas por um recurso ou serviço ambiental e, portanto, o que está recebendo valor não é o meio ambiente ou o recurso ambiental, mas as preferências das pessoas em relação a mudanças de qualidade ou quantidade ofertada do recurso ambiental, que são traduzidas em medidas de bem estar. Ou ainda, segundo o autor, os economistas estimam valores ambientais em termos monetários de maneira a tornar esse valor comparável com outros valores de mercado, de forma a permitir a tomada de decisão envolvendo recursos ambientais, e inserindo de forma realista o meio ambiente nas estratégias de desenvolvimento econômico.

Segundo Serôa da Motta (1998), a necessidade de se valorar os bens ambientais surge da necessidade de se alocar o orçamento de um projeto da melhor forma possível, considerando todos os custos e benefícios a ele associados. A análise de custo/benefício visa atribuir um valor social a todos os efeitos de um determinado projeto, investimento ou política. Os efeitos negativos são encarados como custos e os positivos como benefícios. Como se pretende comparar custos e benefícios, surge a necessidade de expressá-los em uma medida comum, ou seja, em um mesmo numerário ou unidade de conta. Por isso estes custos e bene- fícios são expressos em termos monetários, embora exista uma série de dificuldades no processo de valoração.

A valoração econômica ambiental é baseada nas teorias microeconômicas do bem-estar, ou seja, quando a disponibilidade de um bem ou serviço ambiental é alterada, a valoração desta alteração deverá mensurar as variações de bem-estar que esta alteração de disponibilidade resultou (Serôa da Motta, 1998). Mas a escolha do melhor método de valoração para ser aplicado num estudo de caso é subjetiva, e deve-se fazê-la segundo os dados e recursos disponíveis, buscando sempre reafirmar os objetivos sociais de eqüidade e sustentabilidade.

Existem vários métodos de valoração ambiental, classificados como diretos e indiretos (Serôa da Motta, 1998). As metodologias de valoração ambiental com base nos custos de saúde, também chamadas de capital humano, ou de produção sacrificada são consideradas na literatura consultada como um método indireto de valoração. A Teoria do Capital Humano supõe que uma vida perdida representa um custo de oportunidade para a sociedade equivalente ao valor presente da capacidade desse indivíduo de gerar renda (Ortiz, 2003). Assim, no caso de morte prematura, esse valor presente representaria a renda ou a produção perdida, considerada uma aproximação para o Valor de uma Vida Estatística (VVE), que pode ser definido, segundo o autor, como a soma dos valores individuais associados à redução do risco de uma morte na sociedade.

Já no caso das metodologias com base nos custos do controle da poluição, não há um consenso entre os autores sobre a classificação deste método. Mas ele se aproxima bastante do método dos gastos defensivos ou custos evitados, que procura estimar os gastos que seriam incorridos em bens substitutos para não alterar a quantidade consumida ou a qualidade do recurso ambiental analisado. Alguns autores, como Wang e Santini (1995) o consideram um método de preferência revelada, pois ao definir os padrões máximos de emissões, a sociedade, através da legislação, determina a meta a ser alcançada pelos sistemas de controle de emissões e, em conseqüência, seus custos. Desta forma, a sociedade estaria determinando o valor que deve ser gasto com a tecnologia de controle, e assim, revelaria o valor monetário que ela estaria alocando às emissões.

Segundo vários autores, está em curso um processo de mudança de paradigma no pensamento econômico. Por um lado, os economistas neoclássicos do main stream dialogam com a questão ambiental, porém sem apresentar uma solução teórica que dê conta de incorporar o meio ambiente sem colocar em cheque seus fundamentos. E por outro lado, surgem novas tentati- 
vas de reincorporar a Natureza no pensamento econômico, como a Economia Ecológica, porém ainda sem um arcabouço teórico que dê conta da questão. Assim, neste contexto de transição, a valoração ambiental, embora seja uma tentativa artificial e conservadora de incluir o meio ambiente na análise econômica, atribuindo valores monetários aos recursos ambientais, ela é considerada por muitos, uma maneira pragmática de lidar com o problema da degradação ambiental.

No Quadro 1 são apresentados alguns métodos de valoração ambiental para estimar os custos da poluição do ar em projetos de transportes e um breve comentário sobre as vantagens e desvantagens de cada um deles. Os métodos disponíveis na bibliografia são bastante complexos, e envolvem muitas incertezas. Eles implicam em um árduo trabalho interdisciplinar, utilizando conceitos e profissionais de vários setores do conhecimento, e também muito tempo e recursos. A prática internacional mostra que estudos deste porte são feitos quase que exclusivamente nos países desenvolvidos, enquanto que aqui nos países em desenvolvimento os resultados costumam ser adaptados daqueles. Mas são muitos os fatores que envolvem tais adaptações, principalmente o fato de a poluição do ar e seus efeitos estarem intimamente relacionados aos padrões de vida da população, seus hábitos e padrões de consumo, que são imensamente diferentes entre os países ricos e pobres. Outra grande dificuldade quanto à adaptação dos valores também se dá quanto ao grau de exposição aos poluentes, quando se trata de países de diferentes climas. Nos países tropicais, de clima quente, vive-se muito mais em ambientes externos, o que aumenta a exposição das pessoas à poluição do ar.

Funções de dose-resposta desenvolvidas para países ricos também não podem ser utilizadas diretamente em países pobres, pois os fatores individuais e sociais destes últimos levam a uma maior incidência de doenças e mortes para os mesmos níveis de concentrações de poluentes. Sempre há um grande aumento da incerteza nos resultados devido a essa série de adaptações.

Alguns métodos apresentados no Quadro 1 envolvem várias etapas de cálculo e estimativas, e cada uma delas pode incorrer num determinado erro estatístico. Esta seqüência de etapas em alguns processos de cálculo acaba incontrolavelmente por multiplicar este erro. Não se pretende estimá-lo numericamente aqui. O que podemos afirmar é que, no final das contas, as estimativas dos valores monetários das emissões segundo estes métodos podem somente indicar a magnitude do problema ambiental que se tem em mãos, tamanho o erro estatístico que pode estar embutido nos resultados.

\section{O MÉTODO PROPOSTO}

No método proposto, considerou-se como ponto de partida, um cenário no qual as emissões veiculares totais teriam sido reduzidas a um nível seguro, ou seja, a poluição do ar por fontes móveis estaria controlada e não haveria mais doenças e mortes devido a estas fontes. Neste cenário, o custo da poluição do ar em termos de danos na saúde e no desgaste de materiais se-

Quadro 1. Avaliação das vantagens e desvantagens dos métodos para estimativa dos custos da poluição do ar em projetos de transportes

\begin{tabular}{|c|c|c|}
\hline Método & Vantagens & Desvantagens \\
\hline $\begin{array}{l}\text { Custos dos Danos em Saúde ou Capital } \\
\text { Humano }\end{array}$ & $\begin{array}{l}\text { - é um método consagrado e aceito interna- } \\
\text { cionalmente; } \\
\text { - é o método mais elaborado de todos e } \\
\text { bastante citado na bibliografia sobre o } \\
\text { tema; }\end{array}$ & $\begin{array}{l}\text { - elevado consumo de tempo e de recursos; } \\
\text { - pouca precisão dos resultados; } \\
\text { - problemas éticos e morais em valorar a vida } \\
\text { humana; } \\
\text { - pouca disponibilidade de dados nos países em } \\
\text { desenvolvimento. } \\
\text { - nunca se consegue avaliar todos os danos, pois } \\
\text { sempre há danos indiretos que se propagam, } \\
\text { formando um conjunto aberto. }\end{array}$ \\
\hline Disposição a Pagar & $\begin{array}{l}\text { - considera o ponto de vista do indivíduo; } \\
\text { - além das perdas materiais, este método } \\
\text { valora também as perdas de ordem afeti- } \\
\text { va, o medo, a dor e as perdas na qualida- } \\
\text { de de vida; }\end{array}$ & $\begin{array}{l}\text { - problemas éticos quanto às diferenças de valor } \\
\text { entre a vida do rico e a do pobre; } \\
\text { - dificuldades de um indivíduo em avaliar riscos; }\end{array}$ \\
\hline Preços Hedônicos & $\begin{array}{l}\text { - não valora a vida humana; } \\
\text { - existe metodologia consolidada e é bas- } \\
\text { tante citado na bibliografia sobre o tema. }\end{array}$ & $\begin{array}{l}\text { - considera que o mercado de imóveis é sempre } \\
\text { sensível à variação da poluição do ar; } \\
\text { - alta correlação entre a poluição do ar e outros } \\
\text { impactos do tráfego intenso de veículos no va- } \\
\text { lor dos imóveis; } \\
\text { - dificuldades na obtenção dos valores dos preços } \\
\text { de mercado dos imóveis. }\end{array}$ \\
\hline Consumo Per Capita & - evita a valoração direta da vida humana; & $\begin{array}{l}\text { - aborda somente as perdas materiais; } \\
\text { - método muito simplista; }\end{array}$ \\
\hline Custos do Controle & $\begin{array}{l}\text { - facilidade na obtenção dos dados; } \\
\text { - exige poucos recursos; } \\
\text { - usa variáveis familiares aos técnicos de } \\
\text { transportes; }\end{array}$ & $\begin{array}{l}\text { - pode enfrentar resistências quanto a mudanças } \\
\text { de abordagem; } \\
\text { - precisa ganhar maturidade utilizando-o em } \\
\text { projetos variados e comparando os resultados } \\
\text { com outros métodos. }\end{array}$ \\
\hline
\end{tabular}


ria nulo, pois todo o custo da poluição do ar teria sido internalizado pelo sistema de controle. Esta é a situação desejada, a meta final do Proconve, e uma realidade em muitos países desenvolvidos: carros limpos, poluição do ar controlada e o fim das doenças e mortes provocadas pelas altas concentrações de gases e partículas poluentes na atmosfera.

Ainda há muito que se fazer para que este cenário seja atingido na grande maioria dos países em desenvolvimento. No Brasil, apesar dos automóveis novos já saírem de fábrica com fatores de emissão bastante baixos, as emissões totais ainda são muito elevadas, pois ainda é muito alta a participação de carros velhos (anteriores a 1986) na frota do país. Falta ainda a implantação do Programa Anual de Inspeção Veicular para obrigar os proprietários dos automóveis a manterem seus veículos com baixos níveis de emissão, o que implicaria em trocar os catalisadores sempre que estiverem vencidos, e manter o motor devidamente regulado. Mesmo assim, ainda serão necessários muitos esforços para viabilizar este cenário, principalmente em fiscalização e em algum programa que acelere a renovação da frota, por exemplo.

Independentemente de este cenário acontecer ou não na prática, é nele que se baseia a presente hipótese: frota de automóveis totalmente equipada com o sistema de controle de emissões no estado-da-arte e funcionando plenamente, e redução das emissões veiculares a níveis tais que as concentrações de poluentes atmosféricos não ultrapassariam nunca os padrões máximos estabelecidos pelo CONAMA. Para que sejam garantidos os níveis de concentração de poluentes dentro do que é considerado seguro para a saúde humana, não devem ser ultrapassados os padrões secundários de qualidade do ar (CETESB, 2006). Assim, os custos da poluição do ar recaem totalmente no sistema de controle de emissões, e os custos de saúde podem ser considerados nulos.

\subsection{Formulação do método proposto}

No método proposto, os custos do controle das emissões veiculares são calculados com base nos custos dos equipamentos de controle das emissões, mais especificamente, no custo dos catalisadores. Esta simplificação foi adotada porque o catalisador é o equipamento mais importante do sistema de controle das emissões veiculares, e também porque ele apresenta preço de mercado mais elevado, em média $\mathrm{R} \$$ 860,00 segundo pesquisa feita pelo autor no mercado de São Paulo, e vida útil relativamente mais curta: em torno de 80.000 quilômetros, conforme informação do fabricante. O canister e a sonda lambda, que também fazem parte do sistema de controle de emissões, têm custo muito baixo, e o sistema de injeção eletrônica tem outras funções além da redução das emissões e, além disso, sua vida útil é muito mais longa que a do catalisador, o que resultaria num custo por quilômetro muito pequeno, não representativo para este tipo de estudo. Considerou-se também um custo institucional referente ao controle das emissões, custo este que inclui os custos de implantação, manutenção e fiscalização das emissões veiculares. O valor da taxa de inspeção veicular anual, que em São Paulo deverá ser um valor próximo a R\$ 50,00/ano, foi considerado bastante representativo desta parcela de custos. Para se poder trabalhar com o custo institucional na mesma unidade que o custo do catalisador, aplicou-se um fator obtido pela divisão da vida útil do catalisador pela quilometragem média percorrida por um automóvel durante um ano (na RMSP este valor está em torno de 15.000 $\mathrm{km} / \mathrm{ano}$ ). Multiplicando-se este fator pelo custo da inspeção veicular anual, obteve-se o custo institucional, em reais, proporcional à vida útil do catalisador $(80.000 / 15.000 \cdot \mathrm{R} \$ 50,00=\mathrm{R} \$ 267,00)$.

Assim, os custos do controle das emissões veiculares por quilômetro podem ser estimados a partir da soma direta dos custos dos catalisadores e do custo institucional, dividido pela vida útil do catalisador em quilômetros:

$$
C E V=\frac{P_{c e}}{V U}
$$

onde, CEV: custo das emissões veiculares, em $\mathrm{R} \$ / \mathrm{km}$;

$P_{c e}$ : $\quad$ preço médio de mercado do catalisador + custo institucional

$(\mathrm{R} \$ 860,00+\mathrm{R} \$ 267,00=\mathrm{R} \$ 1.127,00)$

$=>\mathrm{R} \$ 1.130,00$; e

$V U$ : vida útil do catalisador em quilômetros $(80.000 \mathrm{~km})$.

Fazendo esta divisão simples, $C E V=$ $\mathrm{R} \$ 0,014125 / \mathrm{km}$ ou ainda, para que se possa ter maior sensibilidade a este valor: $\mathrm{R} \$ 1,14$ a cada 100 quilômetros, o que representa um custo bastante elevado. Mas este cálculo é incompleto, pois não considera o custo de emissão do veículo parado nos congestionamentos.

Assim, assumindo que o consumo do catalisador é proporcional ao consumo de combustível, uma vez que os poluentes catalisados são os gases resultantes da queima do combustível no motor, utilizamos a metodologia desenvolvida por Szász (2002) para estimativa do consumo de combustível numa rede de tráfego urbana:

$$
\text { Consumo } / \mathrm{km}=A+\frac{B}{V}+C \cdot V^{2}
$$

Sendo, $V$ a velocidade em $\mathrm{km} / \mathrm{h}$; $A$ é uma constante que equivale ao consumo mínimo para vencer as for- 
ças de atrito do veículo; $B$ é uma constante que representa o custo do congestionamento, por o motor ficar operando em ponto morto, e principalmente pela energia despendida em acelerar novamente o carro a cada retomada de velocidade; e $C$ representa o consumo para vencer a resistência do ar, e só tem importância maior quando em velocidades elevadas, tipicamente rodoviárias. Num trecho de extensão $L$ percorrido num tempo $T$, substituindo $V=L / T$ obtemos como consumo:

$$
\text { Consumo } / \mathrm{km} \cdot L=A \cdot L+B \cdot T+C \cdot L \cdot V^{2}
$$

Para um automóvel médio, e considerando $C L V^{2}$ desprezível para velocidades tipicamente urbanas, e: $A=0,05$ litros $/ \mathrm{km}$, e $B=2,00$ litros/hora (Szász, 2002), temos:

$$
\text { Consumo de combustível }=0,05 \cdot L+2 \cdot T
$$

Assim, por analogia, consideramos que o consumo dos catalisadores se daria na mesma proporção, ou seja, uma parcela referente à quilometragem efetivamente rodada e outra ao tempo de funcionamento do motor num deslocamento típico na rede de tráfego urbana, considerando os congestionamentos.

Durante a vida útil do catalisador, então, um veículo padrão deverá consumir o equivalente em litros catalisados por quilômetros rodados e horas:

$$
\text { Consumo }_{v u}=0,05 \cdot V U(\mathrm{~km})+2 \cdot V U \text { (horas) }
$$

onde, Consumo ${ }_{v u}$ (litros): é o consumo total de combustível pelo automóvel, em litros, durante a vida útil do catalisador, ou seja, é o total de litros de combustível cujos gases emitidos foram "catalisados";

$V U(\mathrm{~km})$ : é a vida útil do catalisador em quilômetros;

VU (horas): é a vida útil do catalisador em horas $=V U(\mathrm{~km}) /$ velocidade média numa rede urbana, que está em torno de $34,0 \mathrm{~km} / \mathrm{h}$ na RMSP. O valor da velocidade média na rede pode ser extraído do modelo de simulação utilizado no estudo, ou de outros estudos de velocidade na rede urbana em questão $=80.000 / 34=$ $2.352 \mathrm{~h}$.

O custo total do controle das emissões por litros catalisados pode ser obtido, dividindo-se o valor total do catalisador pelo consumo total de combustível durante a sua vida útil:

$$
\text { Custo / litro }=\frac{P_{c e v}}{\text { Consumo }_{v u}}
$$

onde, Custo/litro: é o custo do controle das emissões por litro de combustível, ou de gases proporcionalmente tratados no catalisa- dor, ou seja, quanto custa "catalisar" 1 litro de combustível;

$P_{c e v}$ : é o valor monetário unitário do controle das emissões veiculares;

Consumo $_{v u}$ : (litros) é o consumo total de combustível pelo automóvel, em litros, durante a vida útil do catalisador, calculado em (5).

Distribuindo-se proporcionalmente o custo do catalisador entre quilômetros rodados e tempo de permanência na rede de tráfego, na equação (4), e aplicandose em (1) para as distâncias totais percorridas na rede e o tempo total de permanência dos veículos nos deslocamentos, tem-se que:

$$
\text { CEV }=0,05 \cdot \text { Custo / litro } \cdot L+2 \cdot \text { Custo / litro } \cdot T
$$

onde, $C E V$ : é o custo total da emissão veicular numa dada rede urbana de tráfego, em Reais;

Custo/litro: é o custo da emissão veicular por litro de combustível consumido;

$L$ : é a distância total percorrida na rede de tráfego urbana, em veículos·km; e

$T$ : é o tempo total de permanência na rede, em veículos·hora.

Os valores de $L$ e $T$ podem ser obtidos nas redes de simulação tradicionalmente utilizadas nos estudos de planejamento de transportes. São valores extraídos diretamente dos modelos matemáticos de transportes, através de cálculos bastante simples, que fazem parte da rotina de trabalho.

Como os projetos de transportes tipicamente estudados interferem diretamente nas distâncias totais percorridas (veículo $\mathrm{km}$ ) e nos tempos totais de viagem (veículohhora), se pode comparar os valores destas variáveis entre os cenários futuros estudados (considerando o projeto) e a situação atual, calcular os custos do controle da poluição em cada cenário pelo método proposto e verificar a diferença entre eles. Desta forma, o benefício ou prejuízo monetário do projeto em termos de redução ou aumento das emissões seria equivalente à diferença no valor do custo do controle da poluição do ar entre o cenário de projeto e a situação atual. Este valor, segundo a presente proposta, equivaleria ao valor monetário do benefício ambiental do projeto, em termos de redução das emissões veiculares, a ser incorporado na análise de viabilidade econômico-financeira. Ou seja, quando há redução deste valor, assume-se que o projeto gera um benefício monetário positivo para a sociedade, proporcional ao valor calculado. Se houver acréscimo no valor monetário da poluição do ar, assume-se que o projeto irá aumentar as emissões e o uso dos catalisadores e impor maiores custos em termos de poluição do ar para a sociedade.

Organizando melhor a fórmula (5), temos: 


$$
C E V(R \$)=\alpha \cdot L+\beta \cdot T
$$

onde,

$$
\begin{aligned}
& \alpha=0,05 \cdot \text { Custo } / \text { litro }=0,05 \cdot \frac{P_{c e v}}{0,05 \cdot V U(k m)+2 \cdot V U(\text { horas })} \\
& \beta=2 \cdot \text { Custo } / \text { litro }=2 \cdot \frac{P_{c e v}}{0,05 \cdot V U(\mathrm{~km})+2 \cdot V U(\text { horas })}
\end{aligned}
$$

Aplicando-se os valores para a realidade de São Paulo, por exemplo, tem-se que:

$$
\begin{aligned}
& \alpha=0,05 \cdot \frac{R \$ 1.130,00}{0,05 \cdot 80.000+2 \cdot 2.353}=0,00649 \\
& \beta=2 \cdot \frac{R \$ 1.130,00}{0,05 \cdot 80.000+2 \cdot 2.253}=0,25960
\end{aligned}
$$

Assim:

$$
C E V(R \$)=0,00649 \cdot L+0,25960 \cdot T
$$

\subsection{Exemplo simplificado de aplicação do método proposto}

Os valores de $L$ e $T$ Foram calculados a partir dos dados dos relatórios do PITU 2020 - Plano Integrado de Transportes para a Região Metropolitana de São Paulo para 2020, para duas estratégias de planejamento, e os valores monetários referentes às reduções das emissões de poluentes são:

Cenário 1: Custo do controle das emissões veiculares em toda a RMSP no ano de 2020, considerando a Estratégia Mínima do PITU:

$$
\begin{aligned}
& C E V(R \$)=0,00649 \cdot L+0,25960 \cdot T \\
& L=19.865 .190 \text { veículos } \cdot \mathrm{km} \\
& L=1.612 .398 \text { veículos } \cdot \text { hora } \\
& C E V_{\text {hora pico }}=R \$ 547.492,20 \\
& C E V_{\text {dia }}=C E V_{\text {hora pico }} \cdot 10_{(\text {fator hora pico) }}=R \$ 5.474 .922,04 / \text { dia } \\
& C E V_{\text {ano }}=C E V_{\text {dia }} \cdot 310_{\text {(dias /ano) }}=R \$ 1.697 .225 .831,63 / \text { ano }
\end{aligned}
$$

Cenário 2: Custo do controle das emissões veiculares em toda a RMSP no ano de 2020, considerando a Estratégia Selecionada do PITU, no cenário de Pleno Desenvolvimento:

$$
\begin{aligned}
& C E V(R \$)=0,00649 \cdot L+0,25960 \cdot T \\
& L=15.352 .684 \text { veículos } \cdot \mathrm{km} \\
& L=1.090 .819 \text { veículos } \cdot \text { hora } \\
& C E V_{\text {hora pico }}=R \$ 382.807,56 \\
& C E V_{\text {dia }}=C E V_{\text {hora pico }} \cdot 10_{\text {(fator hora pico) }}=R \$ 3.828 .075,61 / \text { dia } \\
& C E V_{\text {ano }}=C E V_{\text {dia }} \cdot 310_{\text {(dias /ano) }}=R \$ 1.186 .703 .437,72 / \text { ano }
\end{aligned}
$$

O benefício monetário ambiental anual em termos de redução da poluição do ar devido à implantação plena do PITU 2020 (cenário 2) será de:

$$
\begin{gathered}
\text { Benefício }=R \$ 1.697 .225 .831,63-1.186 .703 .437,72 \\
\text { Benefício }=R \$ 510.522 .393,91 / \text { ano }
\end{gathered}
$$

\section{CONCLUSÕES}

A consistência do método apresentado vem da lógica com que ele foi desenvolvido, a partir das seguintes considerações:

1. Quando toda a poluição é internalizada pelo sistema de controle, os custos de saúde e degradação dos materiais são nulos;

2. Se toda a frota de automóveis for dotada de sistema de controle de emissões, emitindo abaixo dos padrões máximos exigidos pela legislação, a poluição do ar, teoricamente, seria eliminada, e com ela, os custos de saúde;

3. Assim, pode-se estimar os custos da poluição do ar através dos custos do controle das emissões, em substituição aos complexos métodos de cálculo dos custos de saúde.

4. Os custos dos catalisadores e os custos institucionais de implantação, manutenção e fiscalização calculados com base nas taxas de inspeção veicular anual, representam os custos do controle das emissões veiculares;

5. Durante a vida útil de um catalisador, será consumida uma determinada quantidade de combustível pelo automóvel no qual ele está instalado, que calculamos pela fórmula de Szász (2002), e o “consumo” do catalisador deverá ser proporcional a este valor.

É importante destacar que, em se tratando de veículos movidos a combustíveis fósseis, há sempre um custo associado às emissões, que ora pesa sobre a saúde humana e degradação de materiais, quando as emissões são intensas e causam danos, ora sobre o sistema de controle, quando existem programas efetivos de controle das emissões. Dependendo do foco, muda o grupo penalizado. Mas quando um projeto de transporte não poluente é implantado, atraindo viagens que antes eram feitas por modos poluentes (mesmo aqueles com as emissões devidamente controladas, como é o caso dos automóveis com catalisadores), este custo simplesmente deixa de existir a sociedade sai ganhando. Este é o valor monetário que deve aparecer nas análises de viabilidade como um benefício ambiental do novo projeto.

O que se deseja destacar em relação ao método proposto, além da facilidade de cálculo e maior precisão dos resultados, é a sua maior coerência em relação à questão ambiental. Os recursos ambientais são bens públicos, e como tal, não possuem valor de mercado. Os métodos com base nos custos dos danos, inade- 
quadamente, propõem que o mercado pode dar conta de estimar os valores monetários das perdas devido à poluição do ar através dos custos de morbidade e mortalidade: isto aparece, por exemplo, no cálculo do valor da vida humana através dos custos de internações, medicamentos, horas de trabalho perdidas, etc, que são todos valores determinados pelo mercado. Esta tentativa não tem se confirmado como uma verdade.

No método dos custos do controle, é o Estado quem determina os índices máximos de concentrações de poluentes, definindo assim, as metas a serem atingidas pela indústria, e estabelecendo um patamar de custos a ser alcançado. Ou seja, o Estado determina o quanto deverá ser alocado em termos monetários para a redução da poluição. E a questão se volta para a esfera do planejamento, e não do mercado, o que é uma abordagem mais coerente, em se tratando de um recurso ambiental. Em particular e acima de tudo, tal abordagem reconhece que a conservação do meio ambiente, longe de ser apenas uma questão de eficiência econômica, é uma questão de necessidade, uma condição da reprodução social, tratando-se em última instância da própria sobrevivência do homem na Terra cujos recursos tornaram-se limitados.

\section{REFERÊNCIAS BIBLIOGRÁFICAS}

ANTP. Redução das deseconomias urbanas com a melhoria do Transporte Público. SP. Associação Nacional de Transportes Públicos, 1998.

COMPANHIA DE TECNOLOGIA DE SANEAMENTO AMBIENTAL. Relatório de Qualidade do Ar no Estão de São Paulo. SP. CETESB, 2006.

ORTIZ, Ramom Origoni, Valoração Econômica Ambiental, In: Economia do Meio Ambiente, May, P.H., Editora Campus, São Paulo, 2003.

PEARCE, D. Economic Values and the Natural world. Londres, Earthscan Publication, 1993.

RIBEIRO, H.; ASSUNÇÃO, J. V. Historical overview of air pollution in São Paulo metropolitan area, Brazil: influence of mobile sources and related health effects. In: Urban Transport and Environment for the 21st Century III, ed. L. Sucharov and A. Brebbia. Publischer: Computational Mechanics Publication, Southampton, UK.351-60, 2001.

SECRETARIA DE ESTADO DE TRANSPORTE METROPOLITANO. PITU - Plano Integrado de Transportes Urbanos para 2020. 18 ed. São Paulo, 1999. 175 págs.

SERÔA DA MOTTA, R., Manual para Valoração Econômica de Recursos Ambientais, Rio de Janeiro, IPEA/MMA/PNUD/CNPq. 1998.

SZÁSZ, P. A., Balanço Social da CET - Companhia de Engenharia de Tráfego. Relatório Interno CET, São Paulo, 2002.

WANG, M. Q., SANTINI, D. J. e WARINNER, S. A. Monetary Values of Air Pollution in Various US Regions. Transportation Research Record n 1475, 1995. pp33-45. 